\title{
Improvement of cluster-based WSN protocol using fuzzy logic
}

\author{
Jong-Yong Lee ${ }^{1}$, Daesung Lee ${ }^{2}$ \\ ${ }^{1}$ Ingenium college of liberal arts, KwangWoon University, Korea \\ ${ }^{2}$ Department of Computer Engineering, Catholic University of Pusan, Korea
}

\begin{tabular}{|c|c|}
\hline Article Info & ABSTRACT \\
\hline Article history: & A wireless sensor network is a collection of wireless nodes with sensor \\
\hline Received Feb 10, 2020 & $\begin{array}{l}\text { devices that can collect data from the real world. This is because sensor } \\
\text { nodes usually use limited-powered batteries. Therefore, if the battery on the }\end{array}$ \\
\hline Revised Mar 9, 2020 & sensor node is exhausted, the node will no longer be available. If the battery \\
\hline Accepted Apr 5, 2020 & $\begin{array}{l}\text { on some nodes is discharged, the sensor network will not work properly. } \\
\text { To maintain sensor network system, there are many wireless sensor network }\end{array}$ \\
\hline Keywords: & $\begin{array}{l}\text { protocols to increase energy efficiency of nodes. One of the energy-efficient } \\
\text { methods is cluster-based protocols. These protocols divide the sensor fields }\end{array}$ \\
\hline Cluster & into clusters and send and receive data between nodes. Thus, depending on \\
\hline Fuzzy & how the cluster is constructed, the network's lifetime may be reduced or \\
\hline Protocol & configurations. These problems have been improved using fuzzy logic. \\
\hline WSN & $\begin{array}{l}\text { In general, fuzzy logic is used to elect cluster heads based on node residual } \\
\text { energy, node concentration and node centrality. However, it is possible that } \\
\text { nodes close to each other at a high density area are elected as cluster heads. } \\
\text { In this paper, we propose a method to consider the number of adjacent cluster } \\
\text { heads instead of Node Concentration to improve the problem. }\end{array}$ \\
\hline
\end{tabular}

Copyright $(2020$ Institute of Advanced Engineering and Science. All rights reserved.

\section{Corresponding Author:}

Daesung Lee,

Department of Computer Engineering,

Catholic University of Pusan,

57, Oryundae-ro, Geumjeong-gu, Busan, Korea.

Email: dslee@cup.ac.kr

\section{INTRODUCTION}

Wireless sensor network is a network that wirelessly configures sensor nodes that collect data. Sensor nodes can be installed on homes, natural environments, or roads to measure or observe changes. Also, the sensor nodes are wirelessly configured, so they are typically installed in places that are not easily accessible by themselves [1-10]. This kind of wireless sensor network is used in many areas and makes our lives more convenient. Wireless sensor networks have these advantages and disadvantages. Unlike wired networks, wireless sensor networks operate with limited power sources, such as batteries for each sensor node. Once the battery is discharged, the sensor node is no longer available. So it is necessary to optimize energy consumption in order to extend the network's lifetime [11-14]. There are many wireless sensor network protocols to increase the energy efficiency of the network. One of the typical ways to increase energy efficiency is to use cluster-based protocols [15-18]. However, these protocols does not take into consideration the residual energy of nodes or the distance between nodes, consequently clusters could be formed inefficiently. To improve this, Gupta's Fuzzy Logic, LEACH-FL, which considers Node Energy, Node Concentration, and Node Centrality using Fuzzy Logic has been proposed. This helps to form more efficient clusters. However, it may happen that adjacent nodes are elected as cluster heads. If the cluster head nodes are close to each other, they can be configured inefficiently in a cluster configuration. To overcome this, we consider Node Energy, Node Centrality and add new concept, "the number of cluster head(s) to the number of nodes ratio around a cluster head candidate". Process of Fuzzy logic as shown in Figure 1. 


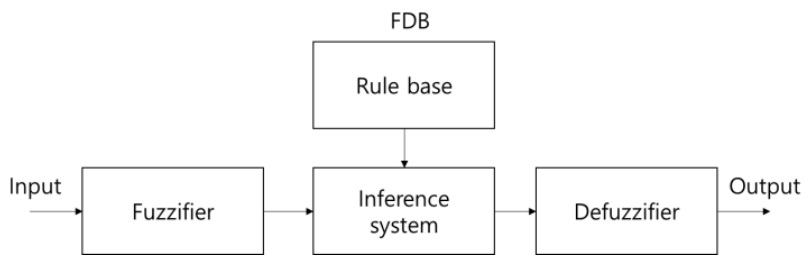

Figure 1. Process of fuzzy logic

\section{RELATED RESEARCH}

\subsection{Fuzzy logic}

The Fuzzy logic [19-30] operation uses Mamdani inference method and goes through the following process:

a) Input variable fuzzification: Determine the extent to which the appropriate fuzzy set belongs to the appropriate set of values entered in the input variable and convert it to a member function.

b) Output rules and aggregation: Consolidate and output inferred results.

c) Defuzzification: Process for converting the output fuzzy values to normal values

d) Calculate using the COG(center-of-gravity) method in defuzzification. COG method is shown in (1).

$$
\operatorname{COG}=\left(\sum \mu_{A}(x) * x\right) / \sum \mu_{A}(x)
$$

\subsection{Gupta's fuzzy logic}

Gupta [31-36] tried to improve the Cluster-based Protocol through Fuzzy logic. The cluster head is elected by fuzzy operation, which takes into residual energy of the node, centrality of the node, and the density of the node. Gupta's Fuzzy Logic has input and output variables as shown in Tables 1, 2, and a fuzzy set as shown in Figure 2. where node density refers to the node density within 20M x 20M space, assuming that the reference node is at the center of the $20 \mathrm{M} \times 20 \mathrm{M}$ space, the density is obtained.

Table 1. Input variable of gupta's fuzzy logic

\begin{tabular}{cccc}
\hline Variable name & \multicolumn{3}{c}{ Set Value } \\
\hline energy & low & med & High \\
concentration & low & med & High \\
centraility & close & adeq & Far \\
\hline
\end{tabular}

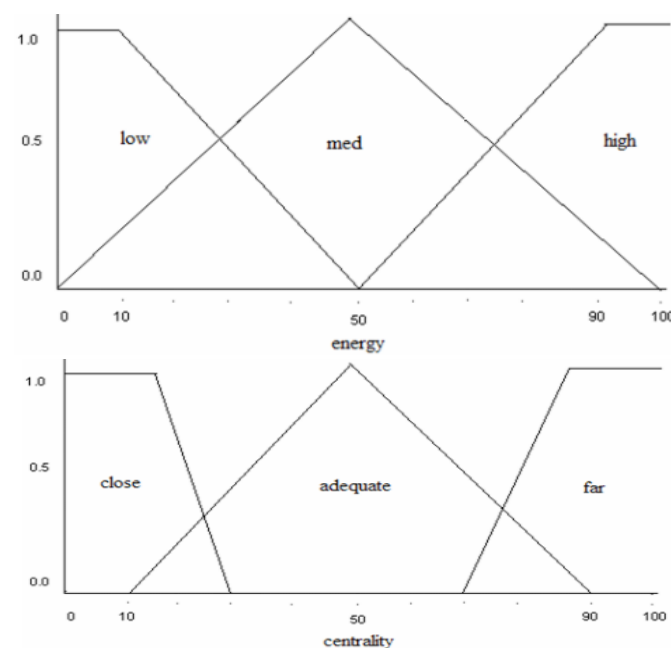

Table 2. Output variable of gupta's fuzzy logic

\begin{tabular}{cc}
\hline Variable name & Set Value \\
\hline & Vsmall \\
& Small \\
chance & Rsmall \\
& Medium \\
& Rlarge \\
& Large \\
& vlarge \\
\hline
\end{tabular}
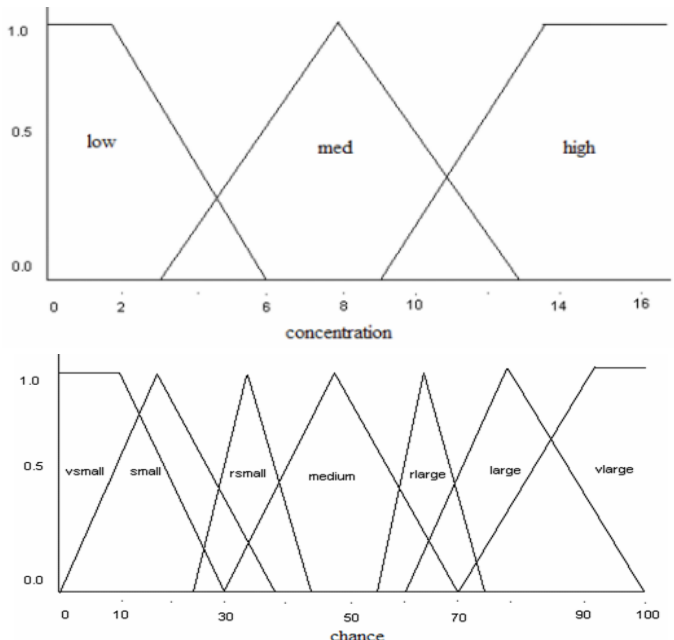

Figure 2. Fuzzy set for input and output variable of gupta's fuzzy logic 
In Gupta's Fuzzy Logic, the chance value for all nodes are calculated for every round. When the chance value calculation is completed, the cluster heads are elected in ascending order of the chance value. The centrality of the node is the sum of the distances from the node located within a certain range $r$ to the node, $\mathrm{A}$ as shown in Figure 3. The range is given by (2).

$$
r=\sqrt{\frac{M}{\pi n P}}
$$

Where $\mathrm{M}$ is the size of the sensor field, $\mathrm{P}$ is the cluster head election probability, and $\mathrm{n}$ is the total number of nodes.

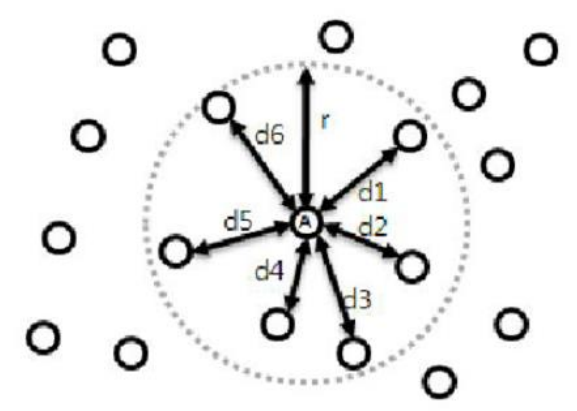

$$
\text { Node Centrality }=d 1+d 2+d 3+d 4+d 5+d 6
$$

Figure 3. Total distance from other nodes in the $\mathrm{r}$ range by node $\mathrm{A}$

\subsection{LEACH-FL}

LEACH-FL [37-43] has input and output variables as shown in Tables 3, 4, and a fuzzy set as shown in Figure 4. Obtain the fuzzy probability value by using the following fuzzy set and following (3).

$$
\text { Probability value }=(\text { Node Energy }) * 2+(\text { Node density })+(2-\text { Node Centrality })
$$

Table 3. Input variable of LEACH-FL

\begin{tabular}{cccc}
\hline Variable name & \multicolumn{3}{c}{ Set Value } \\
\hline Node Energy & 0 (Low) & 1 (Med) & 2 (High) \\
Node Concentration & 0 (Low) & 1 (Med) & 2 (High) \\
Node Centrality & 0 (Close) & 1 (Adeq) & 2 (Far) \\
\hline
\end{tabular}

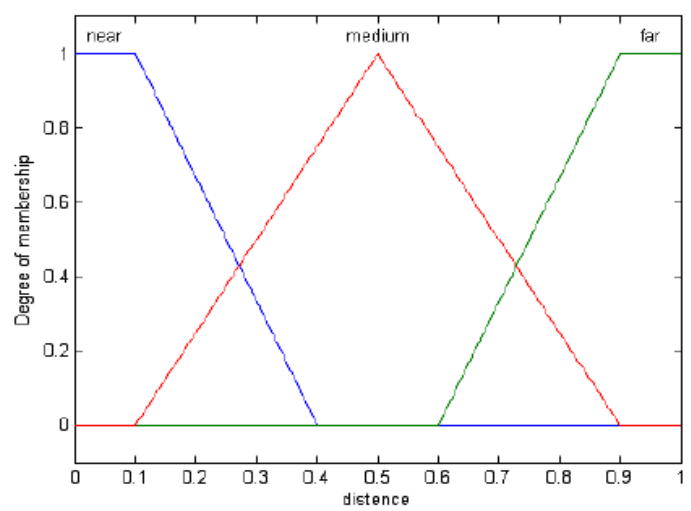

Table 4. Output variable of LEACH-FL

\begin{tabular}{cc}
\hline Variable name & Set Value \\
\hline \multirow{7}{*}{ Probability } & VeryWeak \\
& Weak \\
& LittleWeak \\
& LowerMedium \\
& Medium \\
& HigherMedium \\
& LittleStrong \\
& Strong \\
& VeryStrong
\end{tabular}

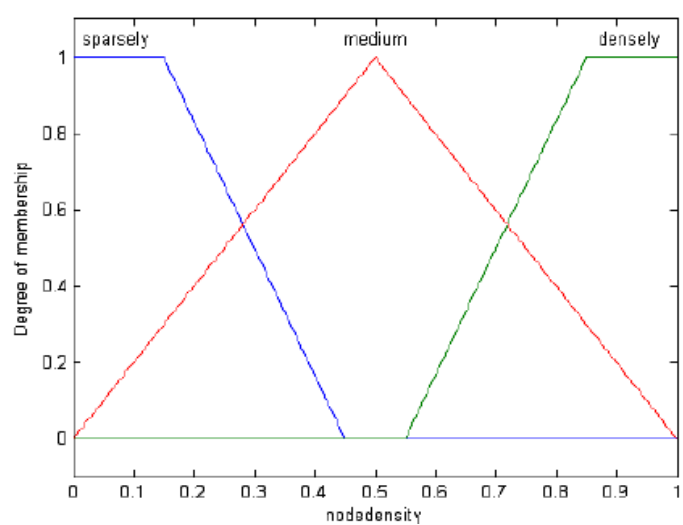



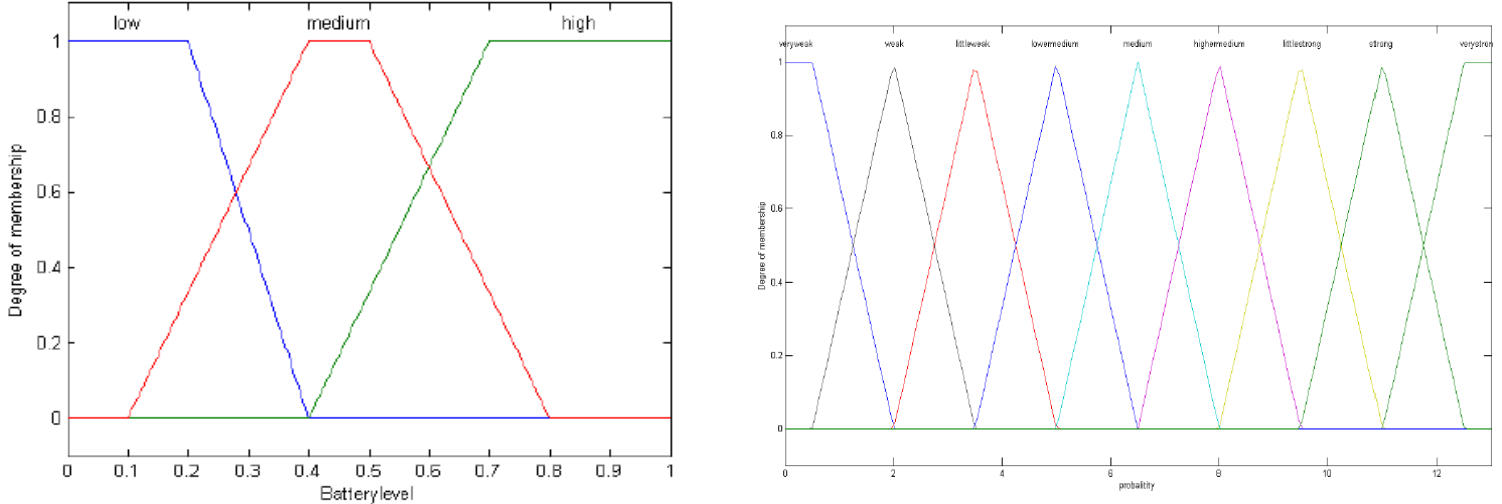

Figure 4. Fuzzy set for input and output variable of LEACH-FL

In the case of LEACH-FL, it operates almost the same as the LEACH Protocol. The LEACH protocol elects the cluster head by comparing the random number of each node with the stochastic threshold (T(n)). However, LEACH-FL elects the cluster head by comparing the calculated fuzzy probability value with $\mathrm{T}(\mathrm{n})$.

\section{PROPOSE METHOD}

The proposed method is to consider the adjacent cluster head nodes instead of Node Concentration in existing LEACH-FL. Fuzzy Logic of the proposed method has input variables as shown in Table 5.

Table 5. Input variable of proposed method

\begin{tabular}{cccc}
\hline Variable name & \multicolumn{3}{c}{ Set Value } \\
\hline Node Energy & Low & Med & High \\
Adjacent CH & Little & Med & Many \\
Node Centrality & Close & Adeq & Far \\
\hline
\end{tabular}

a) Node Energy: The cluster head consumes much energy because it needs to receive data of nodes in the cluster and to aggregate and transmit data. Therefore, the node elected as the cluster head need to have a large residual energy. Node Energy variables as shown in Figure 5.

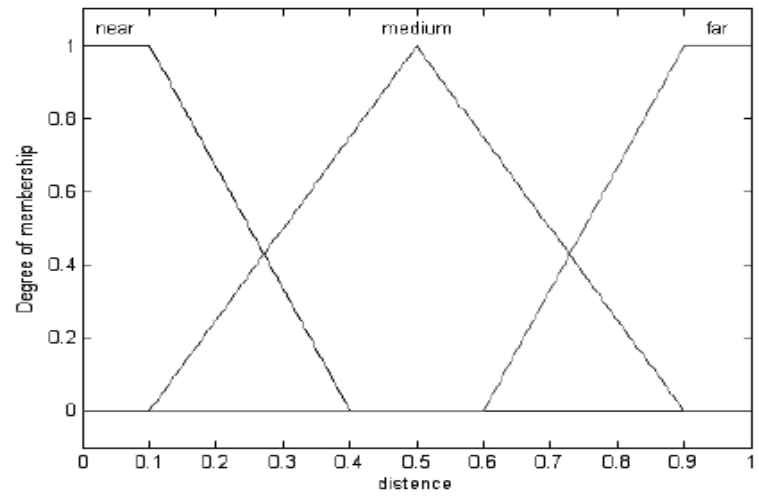

Figure 5. Input variable: node energy

b) Adjacent $\mathrm{CH}$ : the number of cluster head(s) to the number of nodes ratio around a cluster head candidate within the radius $r$. The radius $r$ is given by (2). Distances between the node within $r$ as shown in Figure 6 . The lower the number, the less cluster head nodes are in the vicinity, and the number of cluster heads that are adjacent to each other can be reduced. Adjacent $\mathrm{CH}$ variables as shown in Figure 7. 


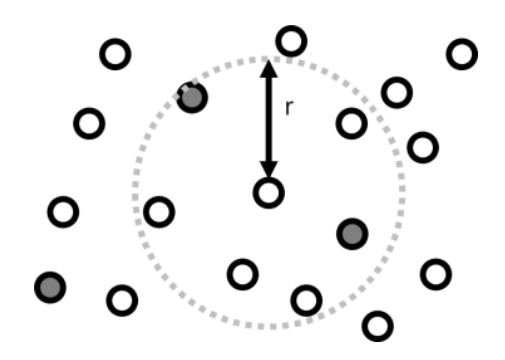

Figure 6. Distances between the node within $r$

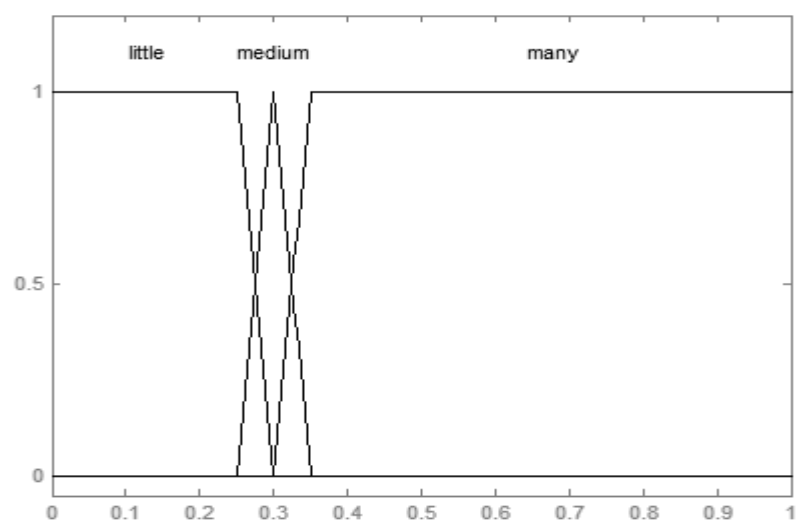

Figure 7. Input variable: Adjacent $\mathrm{CH}$

c) Node Centrality: sum of the distances from nodes located within a certain range $r$ to the node within radius $r$. The lower the value is, the shorter the distance between adjacent nodes is. The radius $r$ is given by (2). As the cluster head is located in the middle of the cluster, the transmission distance of the member node is minimized, which can increase the network lifetime. Node Centrality variables as shown in Figure 8. Fuzzy Logic of the proposed method has output variables as shown in Table 6.

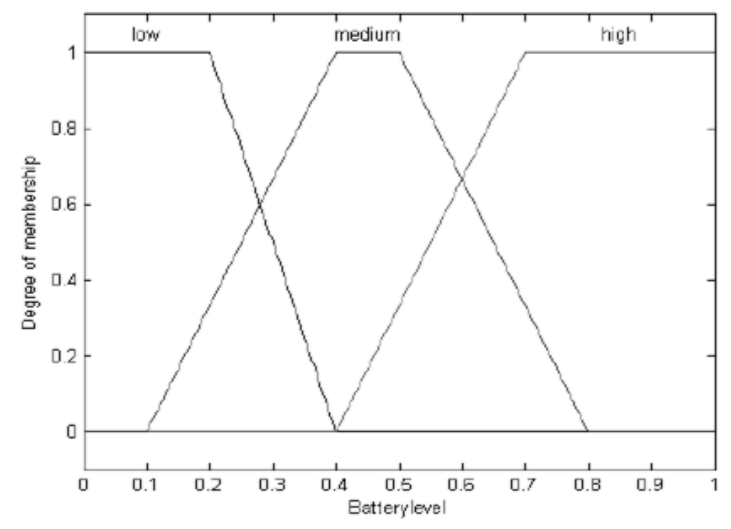

Table 6. Output variable of LEACH-FL

\begin{tabular}{cc}
\hline Variable name & Set Value \\
\hline & Very weak \\
& Weak \\
& Little weak \\
& Lower medium \\
Probability & Medium \\
& Higher medium \\
& Little strong \\
& Strong \\
& Very strong \\
\hline
\end{tabular}

Figure 8. Input variable: node centrality

d) Probability: The output value is determined by fuzzy 3 inputs. The higher this value, the higher the likelihood of being elected to the cluster head. Probability variables as shown in Figure 9.

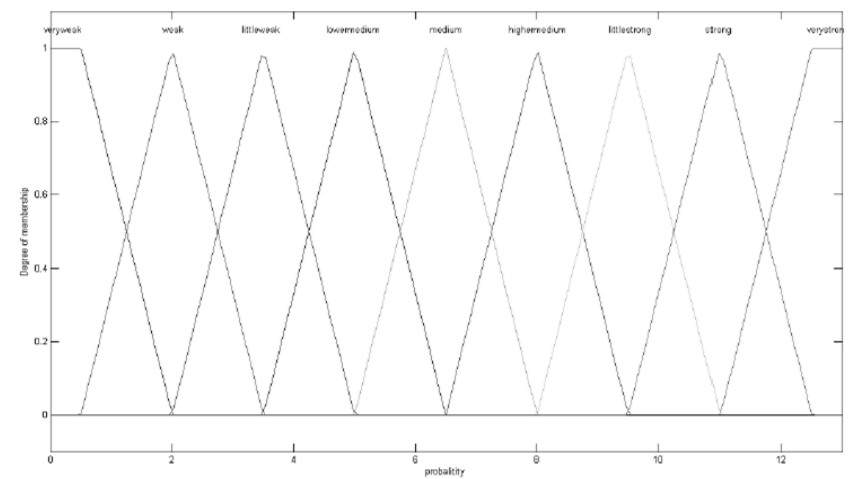

Figure 9. Fuzzy set for output variable of proposed method 


\section{SIMULATION AND RESULT}

\subsection{Simulation}

We compared the network lifetime of the proposed protocol and the existing protocol using Fuzzy Logic. The simulation was conducted when the position of the base station is at the center of the sensor field. Simulation parameters as shown in Table 7 .

Table 7. Simulation parameters

\begin{tabular}{cc}
\hline Parameter & Value \\
\hline$E_{D A}$ & $5 \mathrm{~nJ} / \mathrm{bit} / \mathrm{signal}$ \\
$E_{\text {elec }}$ & $50 \mathrm{~nJ} / \mathrm{bit}$ \\
$\epsilon_{f s}$ & $10 \mathrm{pJ} / \mathrm{bit} / \mathrm{m}^{2}$ \\
$\epsilon_{m p}$ & $0.0013 \mathrm{pJ} / \mathrm{bit} / \mathrm{m}^{4}$ \\
Number of Sensor Nodes & 100 \\
Sensor Field & $100 \times 100$ \\
Location of Base Station & $50,50($ center $)$ \\
Initial Energy & $0.5 \mathrm{~J}$ \\
\hline
\end{tabular}

\subsection{Results}

The network lifetime of the proposed method is 32.6\% higher than Gupta 's Fuzzy logic and 13.3\% higher than LEACH - FL. Simulation results as shown in Table 8. Simulation results as shown in Figure 10.

Table 8. Simulation results

\begin{tabular}{cccc}
\hline & Gupta's method & LEACH-FL & Proposed method \\
\hline FND & 2581 & 3021 & 3423 \\
$80 \%$ Alive & 3754 & 2764 & 3791 \\
\hline
\end{tabular}

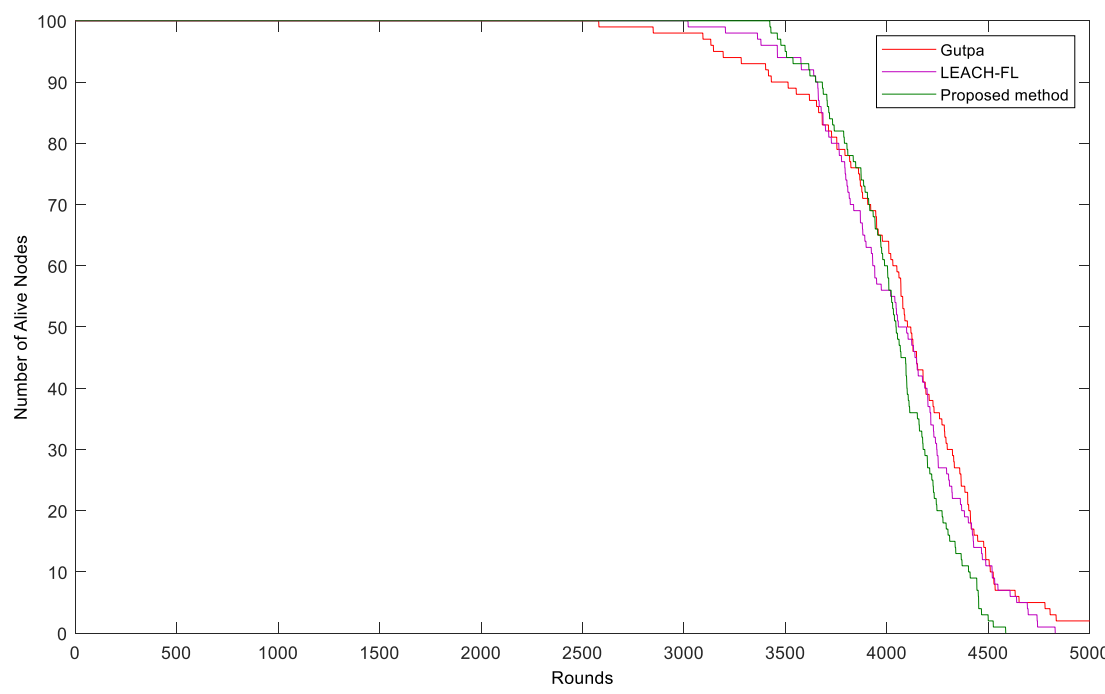

Figure 10. Simulation results

\section{CONCLUSION}

The simulation results show that proposed method has better performance in network lifetime aspect among two protocols using Fuzzy Logic. In the case of a protocol using existing fuzzy logic, the cluster head election probability is increased when node density is high. Considering only the density of nodes without checking whether or not there are nodes elected as the cluster head in the vicinity may cause to be elected cluster heads very close in the high density area. To overcome this, we adjust the cluster head election probability according to the number of nearby cluster heads instead of node density, which resulted in the improvement of the actual network lifetime. 


\section{REFERENCES}

[1] Dargie, W. and C. Poellabauer, "Fundamentals of wireless sensor networks: theory and practice" John Wiley \& Sons Inc., N.Y, 2010.

[2] M. Xiaofeng, Y. Min, M. Dilin, "Application overview of wireless sensor networks," Computer application and software, vol. 25-3, pp. 179-181, 2008.

[3] C. Y. Chong; S. P. Kumar, "Sensor networks: evolution, opportunities, and challenges", Proceedings of the IEEE, vol. 91, pp. 1247-1256, 2003.

[4] David Culler, Deborah Estrin, and Mani Srivastava. "Overview of sensor networks. Computer" pp. 41-49, 2004.

[5] J. Yick, B. Mukherjee and D. Ghosal. "Wireless sensor network survey" Computer networks, pp. 2292-2330, 2008.

[6] I.F. Akyildiz, W. Su, Y. Sankarasubramaniam, and E. Cayirci, "A Survey on Sensor Networks", IEEE Communications Magazine, vol. 40, no. 8, pp. 102-114, 2002.

[7] D Estrin, D Culler, "Connecting the physical world with pervasive networks" IEEE, vol.1, pp. 59-69, 2002.

[8] M. Weiser, "Some Computer Science Issues in Ubiquitous Computing" Comm, ACM, vol. 36, pp. 75-84, 1993.

[9] M.A. Abbas; J.P. Hong. "Survey on Physical Layer Security in Downlink Networks", Journal of Information and Communication Convergence Engineering, vol. 15, no. 1, pp. 14-20, 2017.

[10] H.H. Choi. "Adaptive and Prioritized Random Access and Resource Allocation Schemes for Dynamic TDMA/TDD Protocols", Journal of Information and Communication Convergence Engineering, vol. 15, no. 1, pp. 28-36, 2017.

[11] Kemal Akkaya, Mohamed Younis, "A survey on routing protocols for wireless sensor networks" vol. 3, pp. 325-349, 2005.

[12] S. Mahajan; P. K. Dhiman. "Clustering in Wireless Sensor Networks: A Review”, International Journal of Advanced Research in Computer Science, vol. 7, no. 3, pp. 198-201, 2016.

[13] G. Santhosh Kumar; K. Poulose Jacob; A. Sitara. "Energy Aware Cluster-based Multihop Routing Protocol for Sensor Networks", International Journal of Information Processing, vol. 4, pp. 9-16, 2010.

[14] J.Y. Lee; K.D. Jung; B.Shrestha; J.S. Lee. "Energy Efficiency Improvement of the of a Cluster Head Selection for Wireless Sensor Networks", International Journal of Smart Home, vol. 8, no. 3, pp. 9-18, 2014.

[15] J.Y. Lee. "Energy Improvement of WSN Using The Stochastic Cluster Head Selection", The Journal of The Institute of Internet, Broadcasting and Communication (IIBC), vol. 15, no. 1, pp. 125-129, 2015.

[16] Y.I. Song; K.D. Jung; S.R. Lee; J.Y. Lee. "A Study of Cluster Head Election of TEEN applying the Fuzzy Inference System”, International Journal of Advanced Smart Convergence, vol. 5, no. 1, pp. 66-72, 2016.

[17] W. Heinzelman; A. Chandrakasan; H. Balakrishnan. "Energy-Efficient Communication Protocol for Wireless Microsensor Networks", Proceedings of the 33rd Hawaii International Conference on System Sciences, Maui HI, USA, pp. 10, January 2000.

[18] W.R. Heinzelman, J. Kulik, H. Balakrishnan, "Adaptive protocols for information dissemination in wireless sensor networks" ACM, pp. 174-185, 1999.

[19] Kim, Jong-Myoung, et al. "CHEF: cluster head election mechanism using fuzzy logic in wireless sensor networks," In 2008 10th International Conference on Advanced Communication Technolog, IEEE, pp. 654-659, 2008.

[20] Ran, Ge; Zhang, Huazhong; Gong, Shulan. "Improving on LEACH protocol of wireless sensor networks using fuzzy logic," Journal of Information \&Computational Science, vol. 7, no. 3, pp. 767-775, 2010.

[21] Lee, Jin-Shyan; Cheng, Wei-Liang. "Fuzzy-logic-based clustering approach for wireless sensor networks using energy predication," IEEE Sensors Journal, vol. 12, no. 9, pp. 2891-2897, 2012.

[22] Taheri, Hoda, et al. "An energy-aware distributed clustering protocol in wireless sensor networks using fuzzy logic,” Ad Hoc Networks, vol. 10, no. 7, pp. 1469-1481, 2012.

[23] Logambigai, R.; Kannan, Arputharaj, "Fuzzy logic based unequal clustering for wireless sensor networks," Wireless Networks, vol. 22, no. 3, pp. 945-957, 2016.

[24] Shu, Haining; Liang, Qilian; Gao, Jean, "Wireless sensor network lifetime analysis using interval type-2 fuzzy logic systems," IEEE Transactions on Fuzzy Systems, vol. 16, no. 2, pp. 416-427, 2008.

[25] Haider, Tarique; Yusuf, Mariam, "A fuzzy approach to energy optimized routing for wireless sensor networks," Int. Arab J. Inf. Technol, vol. 6, no. 2, pp. 179-185, 2009.

[26] Mhemed, Rogaia, et al., "An energy efficient fuzzy logic cluster formation protocol in wireless sensor networks," Procedia Computer Science, vol. 10, pp. 255-262, 2012.

[27] Anno, Junpei, et al., "Performance evaluation of two fuzzy-based cluster head selection systems for wireless sensor networks," Mobile Information Systems, vol. 4, no. 4, pp. 297-312, 2008.

[28] Singh, Ashutosh Kumar; Purohit, N.; Varma, S. "Fuzzy logic based clustering in wireless sensor networks: a survey," International Journal of Electronics, vol. 100, no. 1, pp. 126-141, 2013.

[29] Abdulalim, Md Abdul; Wu, Yu Cheng; Wang, Wei, "A fuzzy based clustering protocol for energy-efficient wireless sensor networks, “In: Advanced Materials Research,” Trans Tech Publications Ltd, pp. 685-690, 2013.

[30] Gajjar, Sachin; Sarkar, Mohanchur; Dasgupta, Kankar, "Cluster head selection protocol using fuzzy logic for wireless sensor networks," International Journal of Computer Applications, vol. 97, no. 7, 2014.

[31] I. Gupta; D. Riordan; S. Sampalli. "Cluster-head Election using Fuzzy Logic for Wireless Sensor Networks", Proceedings of the 3rd Annual Communication Networks and Services Research Conference (CNSR'05), pp. 255-260, 2005.

[32] G. Ran; H. Zhang; S. Gong. "Improving on Leach Protocol of Wireless Sensor Networks Using Fuzzy Logic", Journal of Information \& Computational Science, vol. 7, no. 3, pp. 767-775, 2010.

[33] Bhattacharya, Indrajit; Ghosh, Saurav, Kundu, Suparna, "Maximizing lifetime of wireless sensor network through extended LEACH algorithm," In: International Conference on Computer Science and Information Technology, pp. 377-386, 2012. 
[34] Mostafa, Baghouri; Saad, Chakkor; Abderrahmane, Hajraoui, "Fuzzy logic approach to improving Stable Election Protocol for clustered heterogeneous wireless sensor networks," J. Theor. Appl. Inf. Technol, vol. 14, pp. 112-116, 2014.

[35] Maurya, Prashant; Kaur, Amanpreet; Choudhary, Rohit, "Behavior analysis of LEACH protocol," In: 2014 International Conference on Parallel, Distributed and Grid Computing. IEEE, pp. 68-71, 2014.

[36] Kwon, Oh Seok; Jung, Kye-Dong; Lee, Jong-Yong, "WSN Protocol based on LEACH Protocol using Fuzzy," International Journal of Applied Engineering Research, vol. 12, no. 20, pp. 10013-10018, 2017.

[37] Goyal, Rahul, "A review on energy efficient clustering routing protocol in wireless sensor network," In: ijret. pp. 218-221, 2014.

[38] Jung, KyeDong; Lee, Jong-Yong; Jeong, Hwa-Young, "Improving adaptive cluster head selection of teen protocol using fuzzy logic for WMSN," Multimedia Tools and Applications, vol. 76, no. 17, pp. 18175-18190, 2017.

[39] Ajayakumar, C. K., et al. "Optimization of LEACH protocol for effective power utilization in Wireless Sensor Networks," 2013.

[40] Kannan, S., "A novel approach towards achieving energy efficient and load balancing for wireless sensor network used in wearable physiological monitoring," Australian journal of basic and applied sciences, vol. 9, no. 5, pp. 63-71, 2015.

[41] Izadi, Davood; Abawajy, Jemal; Ghanavati, Sara, "A new energy efficient cluster-head and backup selection scheme in WSN," In: 2013 IEEE 14th International Conference on Information Reuse \& Integration (IRI). IEEE, pp. 408-415, 2013.

[42] Sharma, Naveen; Nayyar, Anand, "A comprehensive review of cluster based energy efficient routing protocols for wireless sensor networks," International Journal of Application or Innovation in Engineering \& Management (IJAIEM), vol. 3, no. 1, pp. 441-453, 2014.

[43] El Alami, Hassan; Najid, Abdellah. SEFP, “A new routing approach using fuzzy logic for clustered heterogeneous wireless sensor networks," International Journal on Smart Sensing \& Intelligent Systems, vol. 8, no. 4, 2015.

\section{BIOGRAPHIES OF AUTHORS}

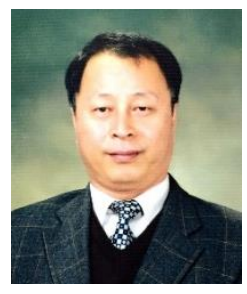

Jong-Yong Lee He received the B.S. degree in Nuclear Engineering from HanYang University, Korea, in 1983, the M.S. and Ph. D degree in Electrical Engineering from KwangWoon University, Seoul, South Korea, in 1986 and 1992. His current research interests include nonlinear system analysis and control, feedback linearization, computer aided control, computer network, image fusion and WSN, Sensor Network.

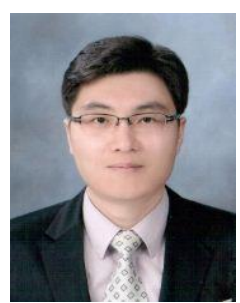

Daesung Lee $\mathrm{He}$ is a professor in the Department of Computer Engineering, Catholic University of Pusan, Korea. He received the B.S., M.S. and Ph.D. degrees from the Inha University, Korea, in 1999, 2001 and 2008, respectively, all in Electrical Engineering Computer Science \& Engineering from Inha University. His research interests include security in network, convergence and operating system. 